\title{
Start-ups, venture capitalists, and the capital gains tax
}

\author{
Christian Keuschnigg a,*, Soren Bo Nielsen ${ }^{\mathrm{b}, 1}$ \\ ${ }^{a}$ University of St. Gallen (IFF-HSG), CEPR and CESifo, Varnbuelstrasse 19, CH-9000 St. Gallen, Switzerland \\ ${ }^{\mathrm{b}}$ Copenhagen Business School, EPRU, CEPR and CESifo, Solbjerg Plads 3, DK-2000 Frederiksberg, Denmark
}

Received 3 March 2002; received in revised form 11 February 2003; accepted 11 February 2003

\begin{abstract}
A model of start-up finance with double moral hazard is proposed. Entrepreneurs have ideas and technical competence, but lack own resources as well as commercial experience. Venture capitalists (VCs) provide start-up finance and managerial support. Both types of agents thus jointly contribute to the firm's success, but neither type's effort is verifiable. We find that the market equilibrium is biased towards inefficiently low entrepreneurial effort and venture capital support. In this situation, the capital gains tax is particularly harmful. The introduction of a small tax impairs effort and advice and leads to a first-order welfare loss. Several other policies towards venture capital and start-up entrepreneurship are also investigated.
\end{abstract}

(C) 2003 Elsevier B.V. All rights reserved.

JEL classification: D82; G24; H24; H25

Keywords: Venture capital; Capital gains taxation; Double moral hazard

\section{Introduction}

Potential entrepreneurs have new ideas but lack own resources as well as commercial experience. The potentially high return of innovative firms is subject to large risks. In the early start-up phase, the product or service is not yet fully developed and the market potential is uncertain. Start-ups require considerable funds to pay for research and development as well as equipment investment which far exceed the entrepreneur's own wealth. They find it difficult, however, to raise outside finance. They cannot offer

\footnotetext{
* Corresponding author. Tel.: +41-71-224-2520/3085; fax: +41-71-224-2670; http://www.iff.unisg.ch. E-mail addresses: christian.keuschnigg@unisg.ch (C. Keuschnigg), sbn.eco@cbs.dk (S.B. Nielsen).

${ }^{1}$ Tel.: +45-3815-2596; fax: +45-3815-2576.
} 
enough collateral to secure business debt, and they are unable to generate sufficient revenue to pay regular interest. They have no own track record that could be assessed by outside investors. The unproven market potential, the technological risks in further product development, and the managerial inexperience of entrepreneurs add up to formidable risks that depend on the quality of the proposed business idea and the entrepreneur's managerial potential. Further, her superior knowledge about the firm creates a possibility for opportunistic behavior that puts the investor's money at risk. The informational disadvantage of outside investors is particularly severe in the case of young innovative firms. Assessing the prospects of such firms requires much business competence and own industry experience on the part of the investor which banks do not have. For these reasons, bank finance is difficult to obtain for innovative start-ups.

Venture capitalists (VCs) have money and industry experience. Their managerial know-how and industry knowledge establishes a comparative advantage over other financial intermediaries in financing young, innovative firms. Kaplan and Strömberg (2001) describe the main functions of VC financing which consist of screening, contracting and advising. VCs carefully screen and select business plans. They have developed sophisticated financial instruments and contractual arrangements to alleviate the problems resulting from informational asymmetries. They add value by establishing contacts, giving strategic business advice, and generally helping in the professionalization of young firms.

This paper focuses on the last function of VC finance, which is an important one ${ }^{2}$. Hellmann and Puri (2002) show empirically that VC backed start-ups in Silicon Valley are much faster in introducing stock option plans for high skilled personnel and in hiring a professional sales manager. Also, the presence of a VC makes it more likely that the entrepreneur is replaced by a professional CEO from outside, if her lack of managerial abilities turns out to be an impediment to the firm's rapid growth. The VC's influence is particularly strong in the early phase of business development, when the informational problems are the largest, but becomes insignificant later on, when the firm has successfully matured. In short, VCs add value and raise the likelihood of success by promoting the professionalization of young firms. Hellmann and Puri (2000) show that VC-backed firms introduce more radical innovations and pursue more aggressive market strategies compared with other start-ups. For example, once a VC joins the firm and provides finance, the probability of introducing the new product on the market jumps up by a factor of more than three! Rapid market introduction is strategically important because the first firm on the market enjoys a first mover advantage. Kortum and Lerner (2000) show that a Dollar of R\&D spending creates more patents and more radical innovations than the same expenditure in other firms. They calculate that VC backed firms account for about $14 \%$ of industrial innovation in the US in 1998, although they spend only about $3 \%$ of all R\&D funds. This empirical evidence shows that venture capital significantly promotes innovation and business growth.

\footnotetext{
2 We abstract from screening and selection problems by assuming uniform quality among entrepreneurs.
} 
Although the volume of funds raised and invested grew dramatically in the late 1990s, the market is still much smaller in Europe ${ }^{3}$. More importantly, a recent empirical study by Botazzi and Da Rin (2002) investigates the performance of firms introduced on the technology stock markets Euro.nm ${ }^{4}$ and finds that VC backed firms have not grown significantly faster and have not performed better than other firms. They conclude that the quality of $\mathrm{VC}$ investments in Europe is a more urgent problem than the sheer volume of funds invested. How is it then possible to strengthen the incentives of VCs to support and advise their portfolio companies more actively? If a firm runs into difficulties, the VC will always want to give advice to prevent business failure and thereby protect her return payment. However, only if she is able to share in the upside potential of the project, she will feel a keen interest to contribute to the firm's success beyond what is needed for a secure return payment. For this reason, equity finance or equity-like instruments like convertible securities are optimal in VC finance ${ }^{5}$.

Not only the entrepreneur, but also the financier, must simultaneously put forth effort to advance the firm's prospects. Since both efforts are largely intangible and not verifiable, the relation between entrepreneur and financier suffers from double moral hazard ${ }^{6}$. Accordingly, the equity shares must be carefully split to set incentives for both parties. The VC must share in the firm's upside potential to strengthen her incentives to provide managerial advice. The entrepreneur's remaining share must be large enough as well to secure an appropriate amount of her effort. Both VC advice and entrepreneurial effort are conducive to the firm's success. With double moral hazard, however, a natural inefficiency arises. Both parties must share the marginal return, while each one bears the entire marginal cost of her extra effort. We find a natural bias towards both low entrepreneurial effort and low managerial support on the part of the VC. It is thus important that policy analysis targets the incentives of both entrepreneurs and financiers. Rather than focusing on the sheer volume of funds raised and invested, policy should consider ways to enhance the quality of VC finance and, in particular, sharpen the incentives of VCs to become more actively involved in their portfolio companies.

$\mathrm{VC}$ investments have been the subject of a considerable literature in finance. Recent theoretical contributions include Repullo and Suarez (1999), Casamatta (2002), Inderst

$3 \mathrm{VC}$ investments amount to more than $1 \%$ of GDP in the US, while the share is only about $0.4 \%$ in Europe. We do not attempt to explain any differences in US or European VC investing. The incentive problems noted in this paper are expected to apply quite generally. Given the underdeveloped state of the VC sector, the problems should be particularly severe in Europe, however.

4 These include the Nouveau Marche (Paris), Neuer Markt (Frankfurt), Nieuwe Markt (Amsterdam), Euro.nm Bruxelles and Nuovo Mercato (Milano).

5 With debt finance, the VC would get a fixed return payment, but would not participate in the extra value she creates by advising the entrepreneur in the good state. See Kaplan and Strömberg (2000) on the predominant use of convertible securities or at least equity-like instruments by US VCs, and Schmidt (2002) on the optimality of such financial instruments.

6 Double moral hazard is a core element of the literature on venture capital mentioned below. The basic incentive problems have been analyzed in the literature on moral hazard in teams, see Holmstrom (1982) and McAfee and McMillan (1991), for some important contributions, and Aghion and Tirole (1994) for an application to innovation finance. None of these two strings of literature have explicitly dealth with the effects of taxes and subsidies. 
and Müller (2002) and Schmidt (2002), among others. Gompers and Lerner (1999, 2001) summarize the literature. This research stresses corporate governance perspectives and investigates the financial instruments that are optimally used in the relationship between entrepreneurs and financiers.

Our paper likewise relates to the literature on financial contracting, reviewed recently by Hart (2001) and Tirole (2001). The focus of our paper is on policy analysis and on the implications of double moral hazard for start-up activity and the quality of $\mathrm{VC}$ finance in industry equilibrium. For this reason, our analysis is restricted to a static, one shot relationship between entrepreneurs and financiers, while the financial contracting literature adopts a more dynamic view, which has two distinct advantages. First, dynamic modeling allows to consider non-linear contracts such as convertible securities which offer more flexibility in allocating cash flow rights conditional on certain events in the firm's history as in Schmidt (2002), for example. Second, a more dynamic model allows for a separate allocation of cash flow and control rights as in Aghion and Bolton (1992), Dewatripont and Tirole (1994), Berglöf (1994), Hellmann (1998) and Tirole (2001). Control rights refer to the right to make strategic decisions conditional on certain events such as the failure to achieve predefined milestones. VCs are often endowed with far reaching control rights that even enable them to replace the entrepreneur with a professional outside manager, if this helps the firm to become more profitable, see Hellmann (1998). Such separation is widespread in the VC industry as is empirically documented by Kaplan and Strömberg (2000). Actual VC contracts thus tend to be more flexible than we assume in our static model. Kaplan and Strömberg (2001, p. 427) emphasize, however, that cash flow and control rights are more like complements rather than substitutes. We conclude that our simpler static model roughly captures the incentive problems between entrepreneurs and VCs. Most importantly, it allows us to model the real effects of venture capital in industry equilibrium and to proceed with an explicit analysis of various policy initiatives.

The academic literature has not yet provided a rigorous analysis of taxation and public policy towards VC-based entrepreneurial activity. The exceptions are Gordon (1998), Poterba (1989a,b). Their analysis discusses the effects of taxes on the supply of funds and the entrepreneur's occupational choice decision while they do not explicitly consider the VC's productive role in supporting and advising start-up firms. Poterba emphasized that a cut in the capital gains tax mainly encourages entrepreneurs to start a firm and, thereby, increases the demand for funds, while it has only a minor effect on the supply of funds. The findings of Gompers and Lerner (1998) are largely in the same vein. With these exceptions, we know of little other work besides our own previous efforts. In Keuschnigg and Nielsen (2001a,b), we examined the effects of government services for information and education of entrepreneurs as well as specialized infrastructure. Keuschnigg and Nielsen (2003) considered the effects of tax policy on entrepreneurial activity and welfare, when only entrepreneurs are subject to moral hazard. This paper importantly extends the previous analysis by including a double moral hazard problem relating to the joint effort of both entrepreneurs and financiers. While the entrepreneur is technologically competent, but lacks commercial experience, the VC can help with business contacts and managerial know-how. But 
she will not automatically incur the required effort, unless she is given strong incentives by sharing in the upside potential of the firm. With this extension, the VC's effort and the quality of VC finance tend to be inefficiently low compared with what would be socially optimal. It is then natural to inquire, if any policy initiatives such as cutting the capital gains tax rate would serve to boost the quality in VC finance ${ }^{7}$.

In our paper we ask how tax policy, and in particular the capital gains tax, affects the formation of young and innovative firms. We consider the implications of taxes for startup activity and welfare in general equilibrium with a large traditional sector and a small sector of VC backed start-up firms. The analysis relates to the entrepreneur's tendency to give up a job in the traditional industry and start a business, but also addresses the incentives of entrepreneurs and VCs to put forth effort. Apart from a general analysis of capital gains taxation, we examine some tax and subsidy schemes, which are intended to strengthen incentives of the two parties to provide more effort and managerial support. We propose a narrowly focused, revenue neutral policy that cuts the capital gains tax rate for VC funds, but involves a tax on their physical investments. We also look at a similar revenue-neutral policy which cuts the capital gains tax for entrepreneurs and finances this by an 'entry tax' on entrepreneurs.

Our main findings are as follows: the introduction of a general capital gains tax discourages both entrepreneurial effort and VC support, retards entrepreneurship, and causes a first-order welfare loss. We then consider several welfare improving alternatives for tax policy that can be made self-financing and need not come at the expense of the general tax payer. A narrowly focused tax relief to VC firms that is financed by a start-up investment tax at the expense of the $\mathrm{VC}$, for example, would strengthen joint efforts and boost welfare. A selective reduction of the capital gains tax on entrepreneurs, financed by an entry tax, would yield similar gains. By the complementarity of efforts, either policy initiative succeeds to strengthen the joint input of both parties. As an extension, we also consider differential taxation of the two components of the entrepreneur's overall compensation, i.e. performance-related capital gains and a fixed up-front payment or base salary. We find that an increase in the capital gains tax harms efforts and welfare even more so, when the base salary remains untaxed. A tax on the base salary, in contrast, stimulates entrepreneurial effort and welfare. The differential taxation of capital gains and base salaries changes the extent to which entrepreneurial compensation is performance-related and, thereby, importantly affects the incentives for effort.

We now introduce the model in Section 2. Section 3 turns to the implications of various alternatives of capital gains taxation for entrepreneurship, VC support, and welfare. Section 4 investigates differential taxation of the separate types of income that the entrepreneur collects from the start-up company. Section 5 concludes.

\footnotetext{
7 The paper by Keuschnigg (2002) discusses similar issues in a richer but more difficult framework. Taxation is shown to affect both the extent of advice per firm as well as the optimal number of firms in a VC's company portfolio. The paper points to a separate distortion in the size of $\mathrm{VC}$ portfolios.
} 


\section{The economy}

\subsection{Overview}

Consider a simple economy with a mass one of agents. Individuals may have a business idea and start a firm in the entrepreneurial sector, or else they prefer a safe job in the traditional sector. An occupational choice decision splits the population into $L$ workers and $E$ entrepreneurs,

$$
1=L+E
$$

Two goods are supplied. One unit of labor yields one unit of the traditional good, which is assumed to be the numeraire. The unit input-output coefficient fixes the wage rate at $w=1$, and aggregate output amounts to $L$. The innovative good pays a relative price $V$. Its production is inherently risky. A start-up is able to produce one good with probability $P>0$, but nothing with probability $1-P$. The success probability $P$ is specified below. By the law of large numbers, a fraction $P$ of entrepreneurs succeeds, yielding an aggregate supply of the innovative good equal to $P \times E$. Denoting demand for traditional goods by $X^{D}$ and for innovative goods by $D$, market clearing requires

$$
D=P \times E, \quad X^{D}=L
$$

Entrepreneurs lack both resources and commercial experience to develop their business idea. They team up with a VC who has managerial know-how and money to pay for the start-up cost. Given a fixed number $N$ of VC firms, each one is involved in funding and advising $E / N$ start-ups on average ${ }^{8}$. The new firm's expected output $P$ results from a joint effort by the entrepreneur who contributes her technological know-how, and the VC who supports the venture with managerial advice. A VC generates a net of tax profit $\pi^{F}$ per project. All start-up firms are assumed symmetric. Dividends are distributed among households, giving $\pi^{F} E=\int_{0}^{1} \Pi^{i} \mathrm{~d} i$ in the aggregate, where $\Pi^{i}=\Pi$ is a uniform dividend per capita from equally distributed ownership of $\mathrm{VC}$ firms 9 .

Disposable income $y^{i}$ of an agent depends on her occupation. Taking account of the price normalization $w=1$, and denoting a possible wage subsidy by $S^{L}\left(S^{L}<0\right.$ indicating a wage tax), income of a worker amounts to $1+S^{L}+\Pi$. Income from start-up firms is divided between entrepreneurs and VCs. Since a firm produces one unit of the innovative good, its value is $V$, if it is successful, and zero, if it fails. A start-up firm thus generates an expected capital gain of $P V-(1-z) I$ over the private start-up cost. Physical investment $I$ uses the traditional good and is possibly subsidized by government at a rate of $z$. Since the entrepreneur has no other income or wealth, she cannot pay for the investment

\footnotetext{
8 We do not explicitly determine an optimal number of portfolio companies per VC as is done in Kanniainen and Keuschnigg (2003). Average portfolio size is implicitly determined in equilibrium.

9 In focusing on the contractual relationship between the entrepreneur and the VC company we ignored the fact that widely dispersed ownership of the VC firm may generate free-rider problems in spending advisory effort. These issues would be absent if the firm were fully owned by a single, risk neutral manager.
} 
expenditure. She thus sells a share $1-s$ to a VC for a price $Q=(1-z) I+B$ which covers the entire start-up cost plus an up-front payment $B^{10}$. With this deal, the entrepreneur's expected income or capital gain amounts to $s P V+B^{11}$. In the presence of taxes, the entrepreneur must pay a capital gains tax on the initial deal, $\tau^{E}(Q-(1-z) I)=\tau^{E} B$, plus a tax upon realization of her remaining share, $\tau^{E} S P$ in expected value. Taking account of a potential lump-sum subsidy $S^{E}$ to entrepreneurs, they derive (on top of the profits $\Pi$ from the $\mathrm{VC}$ sector) an expected disposable income from the firm of

$$
\pi^{E}=\left(1-\tau^{E}\right)(s P V+B)+S^{E}, \quad B=Q-(1-z) I
$$

Given the lump-sum transfer $S^{L}$ to workers, per capita income of agent $i$ in different states is

$$
y^{i}= \begin{cases}1+S^{L}+\Pi & \text { worker, } \\ \left(1-\tau^{E}\right)(s V+B)+S^{E}+\Pi & \text { successful entrepreneur, } \\ \left(1-\tau^{E}\right) B+S^{E}+\Pi & \text { unsuccessful entrepreneur. }\end{cases}
$$

A VC expects a profit, or capital gain, of $\pi^{F}$ per firm. With taxes and subsidies,

$$
\pi^{F}=\left(1-\tau^{F}\right)[(1-s) P V-Q]
$$

where $\tau^{F}$ is the capital gains tax applied to the VC. Complete loss-offset is assumed, allowing VCs to offset losses from unsuccessful firms against the gains from successful ones $^{12}$. Given that a VC generates expected, net of tax gains of $\pi^{F}$ per project, her total capital gains add up to $\pi^{F} \times E / N$.

The government assumes a limited role only. Ignoring the provision of public goods, it raises taxes to pay for various subsidies. The government budget constraint is

$$
\tau^{E}(s P V+B) E+\tau^{F}[(1-s) P V-Q] E=S^{E} E+S^{L} L+z I E
$$

Now use Eqs. (1) and (3)-(6) to write aggregate disposable income $Y$ as

$$
Y=\left(\pi^{E}+\Pi\right) E+\left(1+S^{L}+\Pi\right) L=L+(P V-I) E
$$

\footnotetext{
10 One might argue that entrepreneurs are asked to sell their tradable shares in VC firms at a price equal to $\Pi$ to pay for start-up cost $(1-z) I$. The VC is left to pay $(1-z) I-\Pi$ plus a lump-sum $\tilde{B}$, or $Q=(1-z) I-\Pi+\tilde{B}$ in total. This would only lead to a redefinition of the advance payment, $B=\tilde{B}-\Pi$. The same goes with any initial wealth that the entrepreneur might be able to put up as a collateral.

11 In Section 4, we alternatively interpret $B$ as a base salary subject to wage taxation, leaving expected capital gains of $s P V$ only.

12 The working paper Keuschnigg and Nielsen (2002) also included an analysis of incomplete loss offset. Restricting loss offset encourages managerial advice by making failure more costly, but on the other hand raises the effective burden of the capital gains tax on the VC, which tends to discourage advice.
} 
Agents spend disposable income to buy quantities $D$ and $X$ of innovative and traditional goods, respectively. Equating spending $Y=V D+X$ with income in (7), we have

$$
V(D-P E)+\left(X^{D}-L\right)=0, \quad X^{D}=X+I E
$$

Total demand $X^{D}$ for the traditional good stems from households' consumption $X$ and investment $I$ in the entrepreneurial sector. Walras' Law holds: market clearing $D=P E$ for innovative goods also implies equilibrium in the traditional sector, $X^{D}=L$.

\subsection{Private decision making}

Starting an entrepreneurial firm requires a joint effort by the entrepreneur and the VC. The entrepreneur contributes her technological knowledge; the VC firm helps with managerial and market expertise. Both parties are assumed to incur intangible effort costs that are not verifiable and cannot be contracted upon. Their relationship is subject to a double moral hazard as in Schmidt (2002), Repullo and Suarez (1999) and Lülfesmann (1999), for example. Different from these authors we assume, however, that both inputs are always required simultaneously. The entrepreneur provides effort $e$, and the $\mathrm{VC}$ adds value to the firm in terms of managerial advice $a$, where both inputs are assumed continuous $^{13}$. The success probability of the start-up is specified as

$$
P=P(e, a)=p_{0} e^{\epsilon} a^{\alpha}, \quad \epsilon+\alpha<1
$$

Since the efforts of both parties jointly determine the success probability as in (9), the entrepreneur's expected profit $\pi^{E}$ in (3) depends not only on her own effort, but also on the VC's activity. Similarly, the VC can expect high profits $\pi^{E}$ in (5), only if her advice meets with a hard working entrepreneur.

The venture capital cycle involves a sequence of events as Fig. 1 illustrates: (1) the government sets tax policy; (2) a potential VC firm decides whether to set up a fund for financing entrepreneurial firms; (3) the $\mathrm{VC}$ buys an equity stake $1-s$ at a price $Q$; (4) potential entrepreneurs accept or reject the deal, i.e. agents choose their occupation; (5) VCs and entrepreneurs simultaneously supply effort subject to double moral hazard which yields equilibrium efforts as in a Nash equilibrium; (6) nature resolves risk and, thus, determines outcome; (7) agents choose consumption conditional on their income. As usual, the model is solved backwards.

\subsubsection{Preferences and demand}

For simplicity, agents are endowed with separable preferences over consumption and effort cost $l^{i}$. We normalize the worker's effort to zero, $l^{i}=0$ if $i \in L$. In contrast, the entrepreneur's effort $e$ is continuous and gives rise to linear effort cost, $l^{i}=\beta e, i \in E$, and

13 The working paper version, Keuschnigg and Nielsen (2002), considered only a discrete choice by the entrepreneur (high or low effort), combined with continuous VC advice. With this alternative formulation, the entrepreneur's effort must always be high to yield any positive success probability, which excludes the possibility of inefficiently low entrepreneurial effort. 


\begin{tabular}{c|c|c|c|c|c|c}
$\tau^{i}, S^{i}$ & $\Omega^{F}$ & $1-s, Q$ & $i \in\{L, E\}$ & $e, a$ & nature & income \\
\hline $\mathbf{\square}$ & $\mathbf{0}$ & $\mathbf{\square}$ & $\mathbf{0}$ & $\mathbf{0}$ & $\mathbf{\square}$ & $\mathbf{\square}$ \\
\hline policy & entry & deal & occupation & efforts & risk & consumption
\end{tabular}

Fig. 1. Sequence of events.

$\beta>0$. Finally, when advising start-ups, VC firms also incur an intangible cost of managerial effort which likewise is assumed to be linear, $c^{F}=\gamma a, \gamma>0$.

Consumption demand is decided only after effort has been expended and individual income $y^{i}$ has been determined. At that stage, consumers maximize utility for a given effort level. In general, agents choose demand for the two goods to maximize utility net of the disutility of effort,

$$
U^{i *}=\max _{D^{i}, X^{i}}\left\{u\left(D^{i}\right)+X^{i}-l^{i} \quad \text { s.t. } \quad X^{i}+V D^{i} \leq y^{i}\right\}
$$

Utility is assumed separable and linear in the consumption of traditional goods which eliminates income effects. In our simple general equilibrium framework, we can thus solve separately for equilibrium in the entrepreneurial sector just as in a partial equilibrium model. Since subutility $u\left(D^{i}\right)$ is identical for all agents and satisfies $u^{\prime}\left(D^{i}\right)>0>u^{\prime \prime}\left(D^{i}\right)$, demand for the innovative good is the same for everyone, $D^{i}=D$. It will be convenient to adopt the isoelastic specification $u(D)=\phi^{1 / \eta} D^{1-1 / \eta} /(1-1 / \eta)$ which yields

$$
u^{\prime}\left(D^{i}\right)=V, \quad D=\phi V^{-\eta}
$$

Demand for the traditional good then follows from the budget, $X^{i}=Y^{i}-V D$, and reflects the individuals' different income. Substituting back into the utility function, we obtain indirect utility (conditional on effort)

$$
U^{i *}=y^{i}-l^{i}+C S, \quad C S=u(D)-V D
$$

Consumer surplus associated with consumption of innovative goods, denoted by $C S$, may also be obtained by integrating the inverse demand from (10),

$$
C S=\int_{0}^{D(V)} D^{-1}(z) \mathrm{d} z-V D(V),
$$

where $D^{-1}(z)=u^{\prime}(z)$ is marginal utility from the zth unit of the good. Since agents consume the same quantity $D$ independent of income, $C S$ is likewise the same for all.

\subsubsection{Effort choice}

Funding and advising entrepreneurial firms must be sufficiently profitable; otherwise, VCs would close down operations. To break even, the expected capital gains net of taxes must cover not only the effective price paid for the equity stake, but also the VC's intangible effort cost. The VC's problem consists of structuring the deal, i.e. proposing to 
buy a stake $1-s$ for a price $Q=B+(1-z) I$, and subsequently offering a level of managerial support $a$ to maximize $\Omega^{F} \equiv \pi^{F}-\gamma a$. Using (5), we have

$$
\Omega^{F}=\max _{s, B}\left\{\left(1-\tau^{F}\right)[(1-s) \cdot P(e, a) \cdot V-B-(1-z) I]-\gamma a\right\}
$$

subject to (using $\Omega^{E} \equiv \pi^{E}-\beta e$ )

$$
\begin{array}{ll}
P C^{E}: & \Omega^{E}=\left(1-\tau^{E}\right)[P(e, a) s V+B]+S^{E}-\beta e \geq 1+S^{L}, \\
I C^{E}: & \Omega_{e}^{E}=P_{e}(e, a) \cdot\left(1-\tau^{E}\right) s V-\beta=0, \\
I C^{F}: & \Omega_{a}^{F}=P_{a}(e, a) \cdot\left(1-\tau^{F}\right)(1-s) V-\gamma=0
\end{array}
$$

The VC maximizes her net surplus (expected capital gains minus effort cost) subject to the participation constraint (i) which reflects the entrepreneur's occupational choice. When offering a deal, the VC must also anticipate how the contractual terms affect incentives for effort at a later stage, i.e. she must take account of the incentive constraints (ii)-(iii). At effort stage, agents simultaneously choose effort levels, taking the profit share as predetermined.

Following the principle of backward induction along Fig. 1, we commence with effort choice. At this stage, $Q, B, s$, and $V$ plus policy parameters are all fixed. According to (12), expected indirect utility of an entrepreneur is $\pi^{E}-\beta e+\Pi+C S$ with $\pi^{E}$ given by (3) and (9). The entrepreneur's choice of effort $e$ is thus determined by the first-order condition as stated in the incentive constraint $I C^{E}$ in $(14 \mathrm{ii})^{14}$. Income terms that do not depend on effort drop out from the optimality condition. Taking the VC's level of advice as given, her willingness to expend effort increases with her profit share $s$, while a higher capital gains tax $\tau^{E}$ impairs incentives for effort. Similarly, the VC chooses the level of managerial support to maximize the remaining part of her expected income in (14 iii). Taking the entrepreneur's effort as given, she advises more intensively when she owns a larger share $1-s$ of the firm. A high tax rate on capital gains, in contrast, undermines her interest in supporting the firm. Both efforts are simultaneously chosen and are thus determined in a Nash equilibrium ${ }^{15}$, with closed form solutions given in Appendix A, and comparative statics derived in Appendix B. Clearly, efforts are strategic complements.

\subsubsection{Equity contract}

The next step backwards in Fig. 1 turns to the entrepreneur's occupational choice which is reflected in the participation constraint $P C^{E}$ in $(14$ i). Expected utility from entrepreneurship is $\pi^{E}-\beta e+\Pi+C S$, while a worker's salary yields utility $1+S^{L}+\Pi+C S$. Since $\Pi+C S$ is the same for both occupations, it cannot influence occupational choice and, therefore, cancels from the participation constraint. If the deal is sufficiently generous in

\footnotetext{
14 The second order conditions, $\Omega_{a a}^{F}<0$ and $\Omega_{e e}^{E}<0$ are fulfilled by concavity of $P(e, a)$.

15 There will be a zero-effort equilibrium as well. We, henceforth, concentrate on interior equilibria where both parties supply positive effort.
} 
offering a high residual share $s$ on top of a large up-front payment $B$, potential entrepreneurs will find it attractive to give up a safe job and start a firm.

The contract is determined one step earlier in Fig. 1. Since, by assumption, the entrepreneur possesses no own wealth, the equity injection by the $\mathrm{VC}$ must at least cover the start-up cost $(1-z) I$. Apart from that, the VC obviously wants to obtain a large stake $1-s$ at a small price $Q$ (leaving a small share $s$ to the entrepreneur). In structuring the deal, however, the VC must not only consider how the offer affects the entrepreneur's willingness to accept. She must also anticipate the entrepreneur's and her own incentives to expend effort, once the firm is started and the initial investment costs are sunk. Appendix A derives in (A.3) the equity share. The optimal upfront payment $B$ is read off the entrepreneur's participation constraint in (14 i). Upon using the entrepreneur's condition for optimal effort as in (A.4b), we have

$$
\frac{s^{2}}{(1-s)^{2}}=\frac{(1-\alpha) \epsilon}{\alpha(1-\epsilon)}, \quad B=\frac{1+S^{L}-S^{E}}{1-\tau^{E}}-(1-\epsilon) s P V
$$

The equity share depends only on the relative efficiency of the VC's and entrepreneur's efforts in raising the firm's success probability, and is therefore, independent of tax policy. For example, if both inputs are equally important in raising the expected value of the venture $(\alpha=\epsilon)$, then the optimal equity share is one half. If the entrepreneur's effort becomes relatively more important $(\epsilon>\alpha)$, she receives an increasingly larger share to boost her incentives $(s>1 / 2)$. Taxes, however, do importantly enter the compensation package by influencing the required upfront payment $B$ which is read off the entrepreneur's participation constraint [use (A.4b) in (14 i)]. The VC must thus pay an overall price of $Q=B+(1-z) I$ to cover the start-up investment cost as well.

\subsubsection{Industry equilibrium}

The efforts of entrepreneurs and VCs, $e$ and $a$; the success probability $P$; and the terms of contract $s$ and $Q$ are now all determined. With $E$ projects or start-up entrepreneurs, industry supply becomes $P E$. The induced effort levels and supply depend parametrically on the project value which is equal to the market price $V$ of the innovative good. We assume a competitive VC sector where firms compete down profits from VC investments until they just break even. VC firms must thus generate positive monetary profits to compensate for the intangible effort cost of managerial advice. This yields the 'zero profit' condition $\Omega^{F}=\pi^{F}-\gamma a=0$ as yet another equilibrium restriction,

$$
\pi^{F}=\gamma a
$$

A variation in the competitive venture return $V$, of course, feeds back to the levels of effort on the part of the entrepreneur and the VC. $V$ is thus determined jointly by the free entry, zero profit condition together with the other conditions relating to the venture contract and the levels of effort. The equilibrium number of start-up entrepreneurs then follows from overall demand of innovative goods as in (11), and the market clearing condition $D=P E$. The remaining part of the population turns to safe jobs in the traditional manufacturing sector. 


\subsubsection{Welfare}

An evaluation of policy initiatives requires a welfare measure. By the participation constraint in (14 i), indirect utility in (12) will be equal for workers and entrepreneurs, $U^{* E}=U^{* L}$. Household income includes positive monetary profits from ownership of VC firms. Since these profits are merely a compensation for intangible managerial effort costs, we must subtract them from profits ${ }^{16}$. Adding up indirect utilities of agents, subtracting managerial effort costs, and using $\Pi=\pi^{F} E=\gamma a E$ by the zero profit condition, the welfare measure becomes

$$
U^{*}=U^{* E} E+U^{* L} L-\gamma a E=1+S^{L}+C S
$$

\subsection{Efficiency}

Agents maximize each their own surplus, taking the actions of others as given. Private decisions may not achieve the efficient solution which maximizes the joint surplus of each start-up project. The surplus of entrepreneurs is expected net profits minus effort cost minus foregone wages and transfers, $\pi^{E}-\beta e-1-S^{L}$, which is zero by the participation constraint. Denoting by $R$ net tax revenue or government surplus per firm, $R=\tau^{E}(s P V+B)+\tau^{F}[(1-s) P V-Q]-z I-S^{E}+S^{L 17}$, and adding the VC's part $\Omega^{F}$, the joint surplus per venture is $\Phi=\Omega^{F}+\left(\pi^{E}-\beta e-1-S^{L}\right)+R$, or

$$
\Phi=P V-\beta e-\gamma a-I-1
$$

Quite obviously, the first best effort levels that maximize joint surplus are given by

$$
P_{e}\left(e^{*}, a^{*}\right) V=\beta, \quad P_{a}\left(e^{*}, a^{*}\right) V=\gamma
$$

which compares with $\left(14\right.$ ii-iii), i.e. $\left(1-\tau^{E}\right) s P_{e} V=\beta$ and $\left(1-\tau^{F}\right)(1-s) P_{a} V=\gamma$.

Proposition 1. Efficiency. (a) In the untaxed equilibrium, both entrepreneurial effort and managerial advice are too low, $e<e^{*}$ and $a<a^{*}$. (b) The optimal revenue subsidies to induce the first best levels of effort are given by

$$
\left(1-\tau^{E *}\right) \cdot s=1, \quad\left(1-\tau^{F *}\right) \cdot(1-s)=1
$$

Proof. (a) Compare (19) with the untaxed versions of (14 ii-iii), using shares as in (15). (b) Conditions (19) and (14 ii-iii) yield $e=e^{*}$ and $a=a^{*}$, only if (20) holds.

\footnotetext{
16 VCs are modeled as 'atomless' agents and, thus, do not show up in the resource constraint. At the cost of a considerable increase in complexity, but with no interesting new insight, we could have treated VCs as real persons. In this case, the subtraction of their effort cost would have been obvious.

17 When one more entrepreneur is recruited from the pool of workers, the government pays $S^{E}$ instead of $S^{L}$, yielding a net reduction of the surplus equal to $-\left(S^{E}-S^{L}\right)$.
} 
In the absence of taxes, private efforts are smaller than what is socially efficient. The entrepreneur appropriates only a part $s$ of the full social return $P_{e} V$ from extra effort, while she must bear the full marginal cost. The same holds for the financier. The need to share profits to enlist the partner's effort impairs one's own incentives. The market equilibrium is thus biased towards inefficiently low levels of efforts. Efficiency requires that each partner is full residual claimant on the marginal return of her contribution. Obviously, full residual claims cannot be simultaneously allocated to both partners. The government can, in principle, restore efficiency by strengthening the marginal private return on effort. The optimal policy would have to provide differentiated revenue subsidies at rates determined by condition (20). With this policy, private incentives in (14 ii-iii) are aligned to yield, for any given price $V$, the socially optimal effort levels $e^{*}$ and $a^{* 18}$.

How robust is this bias towards low managerial effort and inferior quality of VC finance? Our assumption that the financier and entrepreneur jointly determine the success probability and must exercise effort simultaneously, is important. Schmidt (2002), for example, assumes sequential efforts, where in a first phase only the entrepreneur's effort is required, while in a second stage the further increase in the value of the firm depends exclusively on the VC's managerial input. With this sequential effort choice, Schmidt (2002) is able to explain the use of convertible debt; in particular, he shows that convertible securities under some circumstances may serve to attain a first best outcome. While convertible debt is certainly a more flexible financial instrument and may allow parties to attain a superior outcome than straight equity finance, the first best result hinges critically on the fact that efforts are never required simultaneously, but only sequentially, see Schmidt (2002, section III.G). Different from Schmidt, we stress the fact that the entrepreneur's effort is critical throughout the company's life. In reality, most business failures are ultimately due to some entrepreneurial management mistake. When the joint efforts of entrepreneur and financier overlap and are required simultaneously, the possible advantage of convertible securities relative to (mixed) equity contracts is reduced. In this case, the basic inefficiency noted above emerges again ${ }^{19}$.

Nevertheless, one might wonder whether the highly sophisticated VC industry could not come up with its own market-based solution. In principle, contracting with a third party might solve this commitment problem ${ }^{20}$. The key idea would be that each party deposits with a competitive outside intermediary upfront, at contracting stage, the expected bonus money that corresponds to the other partner's share in the firm. When it comes to the effort stage, the VC can rely on the third party to reward the entrepreneur's effort. Since the entrepreneur's share in profits is already pre-funded, the VC can claim $100 \%$ of the extra project income resulting from her advice, as is required for efficiency. The same logic would apply to the entrepreneur who could make herself full residual claimant by pre-funding the VC's expected part in the firm's profit. However, this solution is prevented by the fact that the entrepreneur is wealth-constrained and is, therefore, unable to pre-fund.

\footnotetext{
18 Closed form solutions of first best efforts may be obtained by inserting (20) into (A.1).

19 For this reason we are confident that the results derived from a simple equity contract carry over to more complex contractual arrangements.

20 The proposed mechanism reflects ideas in the literature on moral hazard in teams, cfr. Holmstrom (1982) and McAfee and McMillan (1991).
} 
This problem with a market based solution to double moral hazard was recognized, for example, by Aghion and Tirole $(1994)^{21}$.

\section{Taxation of venture capital}

This section turns to comparative static and welfare analysis of alternative tax experiments. We are particularly interested in how a uniform capital gains tax on both entrepreneurs and VCs affects the equilibrium number and the survival prospects of start-ups, and how it affects the involvement of VCs in their portfolio companies. The comparative static analysis below uses 'hats' primarily to denote percentage changes. For instance, $\hat{a} \equiv d a / a$, gives the deviation $d a$ relative to the value $a$ in the initial equilibrium position. Further, we define relative changes in tax rates as $\hat{\tau}^{j} \equiv d \tau^{j} /\left(1-\tau^{j}\right)$. To allow for zero initial values of subsidies, we also define $\hat{S}^{i} \equiv d S^{i}$. We assume that the start-up subsidy is set to zero, $z=0$, in the initial equilibrium. Other policy parameters may be positive initially. Appendix A lists in (A.4) some restrictions that must hold in the initial zero profit equilibrium, and that are useful in signing various comparative static effects as derived in Appendix B.

\subsection{Uniform capital gains tax}

Policy makers and business practitioners often state that a capital gains tax is particularly harmful to $\mathrm{VC}$ activity and to the creation of innovative young firms. What are then the effects, in our framework, on the equilibrium number of start-ups and the quality of VC finance? As a first experiment, we consider the introduction of a uniform tax on entrepreneurs and VCs with full loss offset. Hence, $\tau^{E}=\tau^{F}=\tau$, starting from values of zero. To isolate the tax effects, we assume that revenues are distributed by a uniform transfer to entrepreneurs and workers, $S^{E}=S^{L}=S$. This transfer neither affects occupational choice (see 14 i), nor the incentives of entrepreneurs and VCs to put forth effort. The transfer thus leaves VC profits and the competitive price of innovative goods unaffected. In discussing the capital gains tax, we follow again backward induction as indicated in Fig. 1.

The immediate effect of the capital gains tax is that it impairs the incentives on the part of both entrepreneurs and VCs to expend effort in the firm, see (14 ii-iii) above. Note that

21 In the working paper Keuschnigg and Nielsen (2002), we assumed entrepreneurial effort as discrete, being either high or low (zero). With this alternative formulation, the contract must always assure the entrepreneur's high effort, since otherwise the firm would fail with certainty. With only one high effort level, the entrepreneur's input cannot be underprovided. Consequently, 'efficient contracting' merely requires the VC to prefund the entrepreneur's bonus payment to make herself full residual claimant at effort stage. This market solution was shown to achieve the first best. May be for the reasons just mentioned, such market intermediaries seem not to exist in practice. We showed, however, that government can exactly replicate a hypothetical market solution in terms of an optimally designed tax-subsidy scheme. In the current framework, government again is able to achieve the first best in terms of an optimal tax-subsidy scheme, as we will show below. Tax policy can now achieve more than the market since government is obviously not wealth-constrained, while the wealth constraint prevents entrepreneurs to pre-fund the VC's expected profit share, as would be required for efficiency. 
the equity share is independent of tax policy and only reflects the relative efficiency of the entrepreneurial and managerial inputs. With $s$ fixed, (B.2) in the appendix yields $\hat{a}=\hat{e}$ $=-\hat{\tau} /(1-\epsilon-\alpha)$. When the entrepreneur and her financier both cut back their joint effort, the survival prospects of the venture must suffer, $\hat{P}=\epsilon \hat{e}+\alpha \hat{a}=-\hat{\tau}(\epsilon+\alpha) /(1-$ $\epsilon-\alpha)$. Expecting more moderate capital gains from her share in the firm, and since the tax directly diminishes expected entrepreneurial income relative to wages, entrepreneurs become more reluctant to start a firm and must be offered a larger upfront payment, see (B.4), $B \hat{B}=\hat{\tau}-(1-\epsilon) s P V(\hat{P}+\hat{V})$. Obviously, the deal becomes more expensive for the VC, $\hat{Q}=(B / Q) \hat{B}$. The combined impact of these adjustments on VC profits is given in (B.3), which is stated here for convenience,

$$
\hat{\Omega}^{F}=-[(1-s) P V-Q] \hat{\tau}-Q \hat{Q}+(1-s) P V(\hat{V}+\epsilon \hat{e}) .
$$

Obviously, the tax directly cuts into profits. Second, the VC must offer a bigger upfront payment to the entrepreneur. Third, the tax undermines the entrepreneur's effort and thereby the firm's survival chances ${ }^{22}$.

With the prospect of sizeable losses from portfolio investments, VCs will fund fewer start-ups. Eventually, the supply contraction raises the price of innovative goods, or venture returns, by enough to restore profitability of $\mathrm{VC}$ investments. According to (B.6) in combination with (A. $4 \mathrm{~g})$, venture returns increase in zero profit equilibrium by ${ }^{23}$

$$
\hat{V}=\frac{1+(\epsilon+\alpha) I}{1+I} \hat{\tau}>0
$$

Although higher venture returns would otherwise encourage more intensive effort, the direct tax effect works to reduce it and dominates in (B.2) to retard the equilibrium level of efforts and hence the survival probability,

$$
\hat{a}=\hat{e}=-\frac{I}{1+I} \hat{\tau}<0, \quad \hat{P}=-(\epsilon+\alpha) \frac{I}{1+I} \hat{\tau}<0
$$

As the equilibrium price must increase for VCs to break even, demand for the innovative good is choked off. The size of the entrepreneurial sector shrinks. Since entrepreneurs devote less effort and attention to their projects and receive less managerial support by VCs, fewer start-ups will succeed and mature to production stage. This latter effect works to increase entrepreneurship, since a larger number of start-ups is required to accommodate any given level of demand, when the failure rate is high. Substituting (22) and (23) into (B.8) reveals that the capital gains tax will retard entrepreneurship, as long as the demand elasticity $\eta$ is not too low ${ }^{24}$,

$$
\hat{E}=-\frac{1+(\eta-1)[1+(\epsilon+\alpha) I]}{1+I} \hat{\tau}<0 \quad \Leftrightarrow \quad \eta>\eta^{*},
$$

\footnotetext{
22 Although the tax also discourages the VC's own effort, the effect on her surplus can be ignored on account of the envelope theorem.

23 Eq. (22) may also be computed directly from the equations for $\hat{e}, \hat{Q}, \hat{\Omega}^{F}$ stated above.

24 If $\eta$ is near zero, the price increase would have almost no effect on demand. In this case, a smaller survival rate on account of less advice implies a higher start-up rate to accommodate demand.
} 
where $1>\eta^{*}=(\epsilon+\alpha) I /[1+(\epsilon+\alpha) I]>0$. The capital gains tax always reduces the supply of innovative goods, $\hat{P}+\hat{E}<0$. It also discourages entrepreneurship, except for a very low demand elasticity.

Since transfers boost disposable income, the welfare effect depends on the amount of revenue that the tax raises. Starting from an untaxed equilibrium, there will be no tax base effects. By the government budget constraint in (6), equal to $S=\tau(P V-I) E$ in the present case, the tax raises revenues of

$$
(P V-I) E \hat{\tau}=\hat{S}
$$

Proposition 2. Capital gains tax. (a) A uniform capital gains tax discourages joint effort by the entrepreneur and the VC, raises venture returns, and retards entrepreneurship. (b) Although tax financed transfers boost disposable income, a small tax results in a firstorder welfare loss,

$$
\hat{U}^{*}=\hat{S}-P V E \cdot \hat{V}=-\frac{(1-s) \epsilon+s \alpha}{1-s \epsilon-(1-s) \alpha} I E \hat{\tau}<0
$$

Proof. (a) See Eqs. (22)-(24). (b) Substitute (25) and (22) into (B.9). Using $(1-\epsilon-\alpha) \Psi P V=1+I$ and the definition of $\Psi$ from (A.4g), one obtains (26).

A uniform capital gains tax raises the price of innovative goods and thereby reduces welfare on account of a loss in consumer surplus. This loss is not fully compensated by the increase in disposable income when tax revenue is distributed to households. Even a small tax entails a first-order welfare loss in the neighborhood of the untaxed equilibrium. This welfare result confirms the efficiency analysis in Section 2.3 where we argued that the double moral hazard causes both parties to provide an inefficiently low level of effort. Since they must share the marginal return on their effort while bearing the entire private cost, they contribute less than what would be socially optimal ${ }^{25}$. Consequently, the success rate of new firms is too low. Any policy that discourages joint efforts even more is bound to inflict a first-order welfare loss.

\subsection{Low cost subsidy to venture capitalists}

The fact that effort costs on the part of both entrepreneurs and VCs are intangible and not verifiable excludes the possibility of encouraging joint inputs by subsidizing these costs directly. This leaves only revenue subsidies, or negative capital gains taxes $\tau^{E}, \tau^{F}$ $<0$, to address the lack of entrepreneurial effort and managerial support. Unfortunately, such revenue subsidies tend to be expensive. The cost to the general tax payer could be limited, though, if the beneficiaries can be made to pay themselves for the subsidy. The policies suggested in this and the following subsections build on the key insight that

\footnotetext{
25 In the numerator of (26), $1-S$ is the part of the marginal return to the entrepreneur's increase in effort, which she must cede to the VC. Similarly, $s$ is the part of the return on the VC's extra effort, which spills over, to the entrepreneur.
} 
neither an entry tax $S^{E}<0$ on entrepreneurs (negative transfers) nor a tax $z<0$ on start-up capital investment is harmful to incentives, since these taxes are already sunk when it comes to supply effort.

First consider a targeted tax relief to VCs, $\hat{\tau}^{F}<0$, financed by a tax on start-up investment $^{26}, \hat{z}<0$. Cutting the capital gains tax stimulates VC support which, in turn, boosts the entrepreneurs' incentives, $\hat{a}=-(1-\epsilon) \hat{\tau}^{F} /(1-\epsilon-\alpha)$ and $\hat{e}=-\alpha \hat{\tau}^{F} /(1-\epsilon-\alpha)$ by (B.2). As a consequence, the firm is more likely to succeed. As the entrepreneur expects larger capital gains on her profit share, she is attracted with a smaller up-front payment, yielding $B \hat{B}=-(1-\epsilon) s P V \hat{P}$ in (B.4). On the other hand, the introduction of the investment tax raises start-up cost. In the end, the net effect on $Q=B+(1-z) I$ depends on how big a reduction of the capital gains tax is financed by the investment tax. On the revenue side, the tax cut boosts VC profits. The VC's surplus is further enhanced by the increased survival prospects of the firm on account of the entrepreneur's expanded effort. As the business becomes more profitable, $\mathrm{VC}$ investment activity picks up until venture returns are competed down to the new break-even value.

To find the equilibrium price adjustment, one must take account of the interaction with the government budget constraint that determines the size of the feasible tax cut. Since we allow for non-zero tax rates initially, the equilibrium price response will influence the tax base which determines the feasible size of the tax cut and thereby feeds back on the price response. To resolve this simultaneity, we first derive the log-linearized version of the budget constraint, and then solve it together with the competitive price response in (B.6) for $\hat{V}$ and $\hat{\tau}^{F}$. We arrive at

Proposition 3. Self-financed revenue subsidy to VC firms. (a) A small revenue subsidy to $V C$ firms, $\hat{\tau}^{F}<0$, financed by a tax on start-up investment cost, $\hat{z}<0$, encourages joint effort, reduces venture returns, retards entrepreneurship (at least if the demand elasticity is not much bigger than unity), and boosts welfare. (b) Starting from an equilibrium with optimal subsidies, $s\left(1-\tau^{E}\right)=(1-s)\left(1-\tau^{F}\right)=1$, a further increase in the subsidy boosts joint efforts, unambiguously retards entrepreneurship, but leaves venture returns and welfare unaffected.

\section{Proof. See Appendix C}

The welfare result confirms the insights of Section 2.3 on efficiency. With double moral hazard, none of the parties is able to appropriate the full social returns on extra effort, while they must bear the entire private cost. Contrary to this, efficiency would require that both the entrepreneur and the VC are full residual claimants which is obviously impossible, when both efforts are simultaneously required and determined in a Nash equilibrum. As a result, both the entrepreneur's effort and the VC's managerial support are inefficiently low. Government can partly undo this dilemma by providing a revenue subsidy to the VC and thereby compensating for the external benefits. In strengthening marginal returns, the policy succeeds to expand consulting activity. Since efforts are

\footnotetext{
26 In this subsection, we allow for non-zero values of all policy instruments, assuming for simplicity that $S^{E}=S^{L}$ at the outset.
} 
strategic complements, more managerial support also raises the entrepreneur's incentive to put up more effort. Hence, both inputs are brought closer to the social optimum. The upshot is that this policy can be made self-financing rather than being at the expense of the general tax payer. Since the entrepreneur is wealth constrained, the VC must pay for the extra start-up cost imposed by government. The start-up tax, however, does not harm incentives, because it is already sunk when it comes to supply efforts. This way, the VC pays herself for the revenue subsidy she receives. Obviously, the policy fails to raise welfare further if the subsidies are already at their optimal levels as required for first best efforts, see Proposition 1.

\subsection{Low cost subsidy to entrepreneurs}

The quality of start-up investments could also be improved in providing tax incentives to entrepreneurs. Consider now a cut in the capital gains tax or even a revenue subsidy that is restricted to entrepreneurs, $\hat{\tau}^{E}<0$, and which is self-financed by an 'entry tax' on entrepreneurs, $\hat{S}^{E}<0$, while the tax (or subsidy) on VCs is kept constant, $\tau^{F} \gtrless 0$. It is also assumed that $S^{E}=S^{L}$ initially. We argue that the policy boosts the returns to VC investments, allowing for competitive price reductions of innovative goods, and thereby raising welfare. The direct impact of the tax cut is to sharpen incentives and to promote the entrepreneurial input. Since efforts are strategic complements, the entrepreneur's extra activity also raises the VC's incentive to advise more intensively. By (B.2), $\hat{a}=-\epsilon \hat{\tau}^{E} /$ $(1-\epsilon-\alpha)$ and $\hat{e}=-(1-\alpha) \hat{\tau}^{E} /(1-\epsilon-\alpha)$. The firm's survival prospects improve which boosts the VC's surplus as in (B.3) where $\hat{\tau}^{F}=0$. The other important impact on VC profits stems from the price she must pay for her stake which results from the entrepreneur's participation constraint. From (B.4), we have $Q \hat{Q}=B \hat{B}=\left(\hat{\tau}^{E}-\hat{S}^{E}\right) /$ $\left(1-\tau^{E}\right)-(1-\epsilon) s P V(\hat{P}+\hat{V})$. When the entrepreneur gets taxed less, and when the success rate increases, she will collect extra capital gains from her share in the firm and is therefore attracted with a smaller upfront payment. The VC's surplus accordingly increases. The new entry tax, on the other hand, works in the opposite direction. In the end, the net effect on VC profits and, thus, the extent of the competitive price reduction for the output of start-up firms depends on the size of the tax cut that is feasible with a given entry tax.

Proposition 4. Self-financed revenue subsidy to entrepreneurs. (a) A small revenue subsidy to entrepreneurs, $\hat{\tau}^{E}<0$, financed by an entry tax on entrepreneurs, $\hat{S}^{E}<0$, boosts joint efforts, reduces venture returns, retards entrepreneurship (when the demand elasticity is not much bigger than unity), and raises welfare. (b) Starting from an equilibrium with optimal subsidy rates in place, $\left(1-\tau^{E}\right) s=\left(1-\tau^{F}\right)(1-s)=1$, the effects on venture returns and on welfare are reduced to zero. Joint efforts increase and entrepreneurship unambiguously falls.

\section{Proof. See Appendix C.}

The reasons for these welfare gains are largely the same as in the preceding subsection. Cutting the capital gains tax for entrepreneurs sharpens not only their own incentives. Since efforts are strategic complements, it also induces VCs to support their portfolio firms 
more intensively. Accordingly, the survival prospects of start-up firms improve. To avoid imposing any net cost on the general tax payer, entrepreneurs are made to pay themselves in terms of an entry tax for the capital gains tax cuts they receive. The entry tax is not harmful to incentives, since it is already sunk at effort stage. The general public benefits from lower prices of innovative goods.

\section{Taxation of entrepreneurs}

The basic assumption of the preceding section was that the entire income of entrepreneurs exclusively consists of capital gains that derive from their equity stake in the firm. Entrepreneurs were assumed to earn capital gains in an early stage when they sell the share $1-S$ of their firm to a VC for a price $Q$ that exceeds the initial private investment cost by an amount $B=Q-(1-z) I$. In case the firm successfully matures to production stage, they would earn an extra capital gain from their remaining share equal to $s V$, and zero in case of failure. Rather than literally including an upfront payment, the financial arrangements often allow for a modest base salary of the entrepreneur (see Sahlman (1990), among others). The common feature between such an up-front payment and a base salary is that both are fixed in size and, thus, unrelated to performance. The distinction between an up-front payment and a base salary is quite important for tax purposes, however, since taxes on profits and capital gains may differ from taxes on wage income. For this reason, agents often have a keen interest to transform heavily taxed wages into profit income (e.g. Gordon, 1998). To consider the effect of wage taxation we now interpret the upfront payment $B$ that is not related to performance as wage income of the entrepreneur, subject to ordinary wage taxation at rate $t^{27}$. This new interpretation changes the participation constraint relating to the entrepreneur's occupational choice (note that a worker in the traditional sector also pays a wage tax $t$ ),

$$
P C^{E}: \quad \Omega^{E}=\left(1-\tau^{E}\right) P(e, a) s V-\beta e+(1-t) B+S^{E} \geq(1-t)+S^{L}
$$

The only other change to the model is in the government budget which must now include tax revenues $t(B E+L)$ from wage taxation. Appendix D develops the formal analysis.

With respect to policy effects, taxing the base salary cannot have any impact on incentives for joint inputs since it is unrelated to performance. Eqs. (B.2) still describe the basic determinants of entrepreneurial zeal and managerial support. However, the relative taxation of capital gains and wages potentially influences the structure of compensation that consists of an optimal mix between a profit share and a base salary. If the entrepreneur's capital gains get taxed more heavily, while the wage tax on her base salary is kept constant, it becomes more expensive to compensate entrepreneurs with a higher profit share rather than giving them a base salary. The structure of entrepreneurial compensation shifts towards a higher base salary and a lower profit share, see (D.3b) and (D.4) in Appendix D. With the entire compensation less sensitive to performance, the entrepreneur is confronted with rather weaker incentives for effort while the VC's higher

\footnotetext{
27 We are grateful to a referee for drawing our attention to this case.
} 
stake sharpens her incentives to provide managerial advice. Taxes then shift joint efforts from entrepreneurs to VCs. Whether this is good for welfare or not will probably depend on the relative efficiency of efforts in raising the success rate. To investigate the implications of wage taxation of the base salary, we consider the following two experiments.

\subsection{Uniform capital gains tax}

This first experiment repeats the previous one in Section 3, but now the capital gains tax no longer applies to the base salary. To keep the analysis simple, we consider only a small tax, starting from an untaxed position. Eq. (D.4) verifies that the capital gains tax leads to an increase in the profit share of the $\mathrm{VC}$ at the expense of the entrepreneur. This profit share effect in isolation implies a decline in entrepreneurial effort and more VC support. As in Section 3.1, tax revenues are rebated in lump-sum form to isolate the allocative effects of the capital gains tax. Setting other policy parameters to zero eliminates any revenue response due to changes in tax bases. The government budget constraint for the uniform capital gains tax is $\tau(P V-Q) E=S$ which gives ${ }^{28}$

$$
(P V-Q) E \cdot \hat{\tau}=\hat{S} .
$$

To find the policy's effect on the competitive equilibrium price, one must first determine the impact on VC profits. Note that any increased taxation of entrepreneurial income must be compensated by the $\mathrm{VC}$ to keep the entrepreneur willing to start the firm. A higher capital gains tax on entrepreneurs, therefore, reduces the VC's profit as much as a tax on her own returns. With diminished profits, a number of VCs must exit the business until the reduced start-up activity sufficiently shrinks the supply of the innovative goods and thereby boosts the price by enough to restore profitability. The competitive price in a free entry equilibrium thus emerges from the zero profit condition $\hat{\Omega}^{F}=0$. With a uniform capital gains tax $\left(\hat{\tau}^{F}=\hat{\tau}^{E}=\hat{\tau}\right)$, rearranging (D.5) yields

$$
\hat{V}=\frac{(1-s)(1-\alpha)(\epsilon+\alpha)+(1-\epsilon) s}{1-(1-s) \alpha-s \epsilon} \hat{\tau}
$$

Proposition 5. Capital gains tax with untaxed base salary. (a) A small uniform capital gains tax raises venture returns, reduces the entrepreneur's equity share and strongly discourages the entrepreneur's effort. While the net effect of the tax and the venture return diminishes managerial advice, the VC's higher profit share tends to raise it. When the success probability depends symmetrically on efforts, managerial advice falls. (b) A small capital gains tax results in a first-order welfare loss equal to

$$
\hat{U}^{*}=\hat{S}-P V E \cdot \hat{V}=-\frac{(1-s) \epsilon+s \alpha}{1-(1-s) \alpha-s \epsilon} Q \cdot E \hat{\tau}<0
$$

\footnotetext{
28 The entrepreneur's base salary is now deducted from the capital gains tax base, $P V-B-(1-z) I$.
} 
Proof. See Appendix D.

Comparing with Proposition 2, we thus find that a uniform capital gains tax reduces welfare irrespective of whether the upfront payment $B$, or base salary, is subject to the tax or not. The effects of the tax are rather similar with only one major difference. In attracting entrepreneurs, VCs now rely more on the base salary and correspondingly claim a larger profit share for themselves. The proposed equity contract tends to be less performance-related and thus provides weaker incentives to entrepreneurs while strengthening the interest of VCs to support the firm. When efforts merely shift from entrepreneurs to VCs, the effect on the success probability is likely to be small, however, and is in fact exactly zero when the success probability depends symmetrically on both inputs. The implied change in the profit share has thus only a rather negligible influence on welfare. On the other hand, the uniform capital gains tax directly impairs incentives for joint effort, undermines the likelihood of success, and thereby reduces welfare.

\subsection{Taxation of base salary}

Wage taxation of the base salary is not neutral in our model since it shifts the structure of compensation. It also adds to the total start-up cost and, therefore, should reduce supply of venture capital backed products. A supply contraction boosts the price and thereby, tends to encourage overall effort, on top of shifting effort from VCs to entrepreneurs. So the net effect is not clear. We here wish to study the tax on the base salary in isolation from general wage taxation of outside income in the traditional sector, since the latter would have the obvious effect of pushing agents into entrepreneurship, expanding supply, reducing price and thereby, discouraging efforts. To isolate the effects of taxing the base salary only, we keep wage taxes in the traditional sector fixed. The government budget constraint is now $t B E=S$. Consider an increased tax on the base salary $B$ with neutral revenue rebatement by means of uniform lump-sum transfers, i.e.

$$
B E \cdot \hat{t}=\hat{S}
$$

The tax has no direct consequences on effort, since the base salary is not related to performance. However, compensating the entrepreneur in terms of a heavily taxed base salary is now more costly relative to lightly taxed capital gains. Hence, the structure of compensation shifts in favor of a higher profit share, see (D.4), in exchange for a lower base salary. This shift in the profit share strengthens the entrepreneur's incentives, but weakens the VC's interest in consulting with the firm, see (B.2), with no clear-cut net effect on overall inputs a priori. Obviously, the required increase in the gross base salary erodes VC profits. In (D.5), we read an impact of $\hat{\Omega}^{F}=-B \hat{t}^{29}$. With start-up investments, firms refrain from financing projects until venture returns increase to the break-

\footnotetext{
29 Profits would actually increase if outside wages were taxed as well, giving $\hat{\Omega}^{F}=(1-B) \hat{t}>0$. When the entrepreneur's outside alternative is taxed, she can be attracted to entrepreneurship at lower cost.
} 
even level again. In the competitive, zero profit equilibrium, the tax raises venture returns by

$$
\hat{V}=\frac{1-\epsilon-\alpha}{1-(1-s) \alpha-s \epsilon} \frac{B}{P V} \cdot \hat{t} .
$$

Proposition 6. Taxation of base salary. (a) A small wage tax on the base salary raises venture returns and the entrepreneur's equity share. Both effects encourage entrepreneurial effort while they hold ambiguous incentives for the VC. When the success probability depends symmetrically on efforts, managerial support unambiguously increases. (b) A small tax on the base salary yields a first-order welfare gain equal to

$$
\hat{U}^{*}=\hat{S}-P V E \cdot \hat{V}=\hat{U}^{*}=\frac{(1-s) \epsilon+s \alpha}{1-(1-s) \alpha-s \epsilon} B E \cdot \hat{t}>0
$$

\section{Proof. See Appendix D.}

A wage tax on the base salary is thus seen to improve welfare. The effect is rather indirect, however. In raising the cost of VC finance, it forces a number of VCs to leave the business. Eventually, the reduced supply should raise prices and firm values by enough to restore profitability. Although the market supports only a smaller number of start-ups, each one is more valuable. It is this increase in firm value which boosts incentives for joint effort and thereby raises the success probability. The success rate aggregates the joint inputs. Since efforts are underprovided in the market equilibrium, the success rate is too low initially. Although the policy to some extent merely shifts effort from VCs to entrepreneurs, it also encourages effort on average and raises the success rate, bringing it closer to the socially optimal value. Via this effect, wage taxation of the base salary raises more revenue than what is needed to compensate consumers for the increased prices. Thus welfare improves.

\section{Conclusions}

America's thriving venture capital sector is often considered an important source of the country's competitiveness in innovative industries. Judging from several influential policy documents, policy makers in Europe and many other countries increasingly recognize that venture capital can importantly contribute to the professionalization and growth of young innovative firms and thereby, to sustained innovation and growth in the economy at large. It seems, however, that the American role model of venture capitalism is not easily transferred to other countries. Despite the strong recent growth of the volume of funds raised and invested in Europe, there are several signs that these investments are often not as productive as expected. It seems that among all firms recently launched on Europe's high technology stock markets, venture capital-backed firms have not significantly performed better than other firms. The quality of venture capital investments thus seems a more urgent problem than the sheer volume invested. 
Without claiming to address the disparity in venture capital experience on either side of the Atlantic, we have in this paper looked into some of the factors which determine the quality of venture capital investment. VCs provide more than finance, they also add value to young firms. Therefore, the entrepreneur and the financier jointly contribute to the firm's success. Entrepreneurs contribute the technological idea or innovation, but tend to be commercially inexperienced in their early business career. The VC has money and managerial know-how. She can importantly contribute to the professionalization of the young firm. Their relationship is subject to a double moral hazard, however, since none of these efforts are verifiable and contractible. For this reason, not only the entrepreneur, but also the financier need high powered financial incentives which makes equity (or equity like instruments such as convertible securities) the preferred mode of finance. When returns must be shared, but each partner must bear the entire intangible cost of her own input, joint efforts of entrepreneurs and VCs tend to be underprovided.

This paper considered the role of tax policy to promote the quality of venture capital investments. The major problem is that managerial effort cost is largely intangible and not verifiable which excludes the possibility of directly subsidizing effort cost to induce more involvement in portfolio companies. Similarly, the due diligence and commitment of entrepreneurs comes with a largely intangible cost, cannot be verified, and cannot be the subject of a targeted cost subsidy. One is left with the capital gains tax as a prime candidate for reform. This tax is widely considered to be a major obstacle, but its role in shaping venture capital incentives has not been addressed in the public finance literature. We found, indeed, that even a small capital gains tax involves a first-order welfare loss, because it exacerbates a pre-existing distortion and further diminishes incentives to provide entrepreneurial effort and managerial support. Therefore, the capital gains tax could indeed be a major impediment to the development of a high quality venture capital industry that significantly adds value to young innovative firms.

However, one can go further than merely proposing a cut in the capital gains tax at the cost of the general tax payer. Apart from narrowly limiting the tax break to apply to venture capital funds only or to entrepreneurs only, one may also make it essentially selffinanced by imposing a tax on start-up investment cost of venture capital backed firms, or alternatively an entry tax for potential entrepreneurs. Since the increased start-up cost must be largely financed out of the financier's pocket, it makes VCs pay themselves for the capital gains tax break. Since the tax on start-up or entry costs are already sunk when it comes to decide on efforts, they do not impair incentives, while the capital gains tax cut boosts incentives for effort on the part of both entrepreneurs and VCs. These policies not only encourage entrepreneurial ambitions, but also sharpen incentives for stronger involvement of VCs. However, a vital precondition for such targeted tax policy initiatives is that the start-up investment cost and the base salary components are in fact distinguishable from other cost items, and that entrepreneurs and VCs who qualify for a selective capital gains tax relief, can be readily identified.

We conclude that tax policy holds interesting options to sharpen incentives and to promote more quality in venture capital finance. It would be very important, though, to test empirically whether such tax incentives are indeed effective in raising managerial support. One might find some measures of venture capital involvement such as the number of visits to portfolio companies, time allocated to consulting activities, the 
number of portfolio firms per advisor etc. and test whether there is a significant influence of tax variables.

\section{Acknowledgements}

Comments by two referees, Syed Ahsan, Alan Auerbach, Morten Bennedsen, Roger Gordon, Vesa Kanniainen, Christof Lülfesmann, Petri Niininen, Jeff Strnad, Javier Suarez, as well as participants at the ISPE conference on Taxation and Financial Innovation at UC Berkeley and other conferences, are gratefully acknowledged. EPRU is financed by the Danish National Research Foundation.

\section{Appendix A. Closed form solutions}

The Nash equilibrium in joint efforts discussed in Section 2.2.2 follows from the simultaneous solution of the first-order conditions (14 ii-iii). Using the functional form of $P(e, a)$ in (9) yields:

$$
\begin{aligned}
& e=\left\{p_{0} V \cdot\left[\frac{\left(1-\tau^{E}\right) s \epsilon}{\beta}\right]^{1-\alpha} \cdot\left[\frac{\left(1-\tau^{F}\right)(1-s) \alpha}{\gamma}\right]^{\alpha}\right\}^{1 /(1-\epsilon-\alpha)}, \\
& a=\left\{p_{0} V \cdot\left[\frac{\left(1-\tau^{E}\right) s \epsilon}{\beta}\right]^{\epsilon} \cdot\left[\frac{\left(1-\tau^{F}\right)(1-s) \alpha}{\gamma}\right]^{1-\epsilon}\right\}^{1 /(1-\epsilon-\alpha)}, \\
& P=\left\{p_{0} V^{\alpha+\epsilon} \cdot\left[\frac{\left(1-\tau^{E}\right) s \epsilon}{\beta}\right]^{\epsilon} \cdot\left[\frac{\left(1-\tau^{F}\right)(1-s) \alpha}{\gamma}\right]^{\alpha}\right\}^{1 /(1-\epsilon-\alpha)} .
\end{aligned}
$$

The success probability $P$ results from substituting the solutions for $e$ and $a$ into (9).

In structuring the deal, the $\mathrm{VC}$ takes tax policy and venture returns $V$ as predetermined, and fully anticipates how the terms of contract $s$ and $Q=B+(1-z) I$ will affect efforts at the moral hazard stage. As $Q$ is already sunk at effort stage, it cannot have any impact on incentives. A variation in the profit share, however, affects joint inputs and, therefore, the success probability. Taking account of this, introducing the Lagrange-multiplier $\lambda$ for $P C^{E}$, and considering an interior optimum, the maximization of (14) yields:

$$
\begin{aligned}
& \text { (a) } B: \quad-\left(1-\tau^{F}\right)+\lambda \cdot\left(1-\tau^{E}\right)=0 \\
& \text { (b) } s: \quad\left(1-\tau^{F}\right) V\left[s P_{a} \cdot \frac{\partial a}{\partial s}+(1-s) P_{e} \cdot \frac{\partial e}{\partial s}\right]=0,
\end{aligned}
$$

where the condition for $s$ makes use of (A.2a) and (14 ii-iii). Note that the VC anticipates the effects of a variation of $s$ on efforts at moral hazard stage which are derived below in 
(B.2). Expanding the terms in (A.2b) appropriately to make use of (B.2) and noting $a P_{a}=\alpha P$ and $e P_{e}=\epsilon P$ by (9) yields ${ }^{30}$ :

$$
\frac{s^{2}}{(1-s)^{2}}=\frac{(1-\alpha) \epsilon}{\alpha(1-\epsilon)} .
$$

With the profit share thus determined, the upfront payment $B$ is read off the $P C^{E}$ in (14 i), see (15). Model parameters must be appropriately set to assure a non-negative $B$.

Finally, a zero profit equilibrium as in (16) fulfils some restrictions that will be useful in the comparative static analysis ${ }^{31}$ :

$$
\begin{aligned}
& \text { (a) (9) } a P_{a}=\alpha P, \quad e P_{e}=\epsilon P, \\
& \text { (b) (14ii) } e=\left(1-\tau^{E}\right) s P V \cdot \frac{\epsilon}{\beta} \text {, } \\
& \text { (c) (14iii) } a=\left(1-\tau^{F}\right)(1-s) P V \cdot \frac{\alpha}{\gamma} \text {, } \\
& \text { (d) (14) } Q=(1-\alpha)(1-s) P V \Leftrightarrow \Omega^{F}=0, \\
& \text { (e) }\left(\frac{b}{d}\right) \quad e=\left(1-\tau^{E}\right) \frac{s}{1-s} \frac{\epsilon}{1-\alpha} \frac{Q}{\beta} \text {, } \\
& \text { (f) }\left(\frac{c}{d}\right) \quad a=\left(1-\tau^{F}\right) \frac{\alpha}{1-\alpha} \frac{Q}{\gamma}, \\
& \text { (g) } \quad P V=\frac{(1-z) I+\left(1+S^{L}-S^{E}\right) /\left(1-\tau^{E}\right)}{(1-\epsilon-\alpha) \Psi}, \quad \Psi=\frac{1-s \epsilon-(1-s) \alpha}{1-\epsilon-\alpha}>1 \text {. }
\end{aligned}
$$

The last condition follows by substituting for $Q$ in (A.4d) and replacing $B$ from (15). The assumption in (9) together with $0<S<1$ implies $\Psi>1$.

\section{Appendix B. Comparative statics}

Appendix B prepares the comparative statics of the policy scenarios given in Sections 3 and 4. We also use the functional form noted in (9), giving $\hat{P}=\epsilon \hat{e}+\alpha \hat{a}, \hat{P}_{e}=-(1-\epsilon)$ $\hat{e}+\alpha \hat{a}$, and $\hat{P}_{a}=\epsilon \hat{e}-(1-\alpha) \hat{a}$.

Joint effort: As discussed in Section 2.2.2, the incentive constraints (14 ii-iii) simultaneously determine $a$ and $e$. The linearized reaction functions are:

$$
\begin{array}{ll}
I C^{E}: & (1-\epsilon) \hat{e}=\alpha a+\hat{s}+\hat{V}-\hat{\tau}^{E}, \\
I C^{F}: & (1-\alpha) \hat{a}=\epsilon \hat{e}-\frac{s}{1-s} \hat{s}+\hat{V}-\hat{\tau}^{F} .
\end{array}
$$

\footnotetext{
30 First, expanding by $\epsilon-s=1-s-(1-\epsilon)$ yields $(1-\epsilon) s \alpha=(1-s)[s \alpha+(1-\mathrm{s}-\alpha) \epsilon]$, or, after rewriting the square bracket, $(1-\epsilon) s \alpha=(1-s)[(1-\epsilon) s \alpha+(1-\alpha)(1-s) \epsilon]$. Putting the first term in the square bracket on the other side of the equation yields the desired result.

31 Multiply (14 ii) by $a$ and use (A.4a) to get (A.4b). (A.4c) similarly follows from (14 iii). Replace $a$ by (A.4b) in (14) to get (A.4d) for $\Omega^{F}=0$.
} 
Solving the system (B.1) for the equilibrium response of $\hat{a}$ and $\hat{e}$ gives:

$$
\begin{aligned}
& \hat{a}=\frac{1}{1-\epsilon-\alpha}\left[\hat{V}-\frac{s-\epsilon}{1-s} \hat{s}-\epsilon \hat{\tau}^{E}-(1-\epsilon) \hat{\tau}^{F}\right], \\
& \hat{e}=\frac{1}{1-\epsilon-\alpha}\left[\hat{V}+\frac{1-s-\alpha}{1-s} \hat{s}-(1-\alpha) \hat{\tau}^{E}-\alpha \hat{\tau}^{F}\right] .
\end{aligned}
$$

Managerial advice and entrepreneurial efforts are strategic complements. By (B.1), more advice raises the marginal return to the entrepreneur's effort. A higher input by the entrepreneur, in turn, strengthens the VC's advice. This mutual interaction gives rise to the multiplier $1 / 1-\epsilon-\alpha$. The interdependency leads to interesting cross-properties. Raising the tax rate $\tau^{E}$ does not directly affect the VC. However, when the entrepreneur's reward for high effort is taxed and she correspondingly reduces her input, the VC's incentive to support the venture goes down as well.

Zero profit equilibrium: Although policy influences advice, the envelope theorem prevents, on account of (14 iii), that a variation of $a$ affects profits. This is not the case with respect to entrepreneurial effort, however. Accordingly, VC profits in (14) change by:

$$
\frac{\hat{\Omega}^{F}}{1-\tau^{F}}=(1-s) P V(\hat{V}+\epsilon \hat{e})-[(1-s) P V-Q] \hat{\tau}^{F}-Q \hat{Q},
$$

where the profit share remains constant on account of (15). The price of the deal contains the net investment cost plus an upfront payment. By (3) and (15), the investment subsidy reduces the deal price, while a larger upfront payment trivially inflates it:

$$
\begin{aligned}
& \hat{Q}=\frac{B}{Q} \hat{B}-\frac{(1-z) I}{Q} \hat{z} \\
& \hat{B}=\frac{\hat{S}^{L}-\hat{S}^{E}+\left(1+S^{L}-S^{E}\right) \hat{\tau}^{E}}{\left(1-\tau^{E}\right) B}-\frac{(1-\epsilon) s P V(\hat{P}+\hat{V})}{B} .
\end{aligned}
$$

At the date of the VC's entry, the optimal contract and subsequent efforts are all anticipated. In particular, $s$ stays constant so that the informational rent changes with expected revenue of the firm. With $\hat{P}=\varepsilon \hat{e}+\alpha \hat{a}$, one obtains from (B.2):

$$
\hat{P}+\hat{V}=\frac{1}{1-\epsilon-\alpha}\left[\hat{V}-\epsilon \hat{\tau}^{E}-\alpha \hat{\tau}^{F}\right] .
$$

Substitute (B.4)-(B.5) into (B.3), collect terms, set $\hat{\Omega}^{F}=0$, and get the equilibrium price that results from free entry competing profits down to zero. Use (A.4d) to replace $Q$, simplify coefficients, and utilize $\Psi$ to obtain:

$$
\hat{V}=\alpha \hat{\tau}^{F}+\left[\epsilon+\frac{1+S^{L}-S^{E}}{\left(1-\tau^{E}\right) \Psi P V}\right] \hat{\tau}^{E}-\frac{(1-z) I}{\Psi P V} \hat{z}+\frac{\hat{S}^{L}-\hat{S}^{E}}{\left(1-\tau^{E}\right) \Psi P V}
$$


The competitive price adjustment feeds back into joint effort. Substituting (B.6) into (B.2), we get effort levels in zero profit equilibrium:

$$
\begin{aligned}
& \hat{a}=-\hat{\tau}^{F}+\frac{1}{(1-\epsilon-\alpha) \Psi P V}\left[\frac{1+S^{L}-S^{E}}{1-\tau^{E}} \hat{\tau}^{E}+\frac{\hat{S}^{L}-\hat{S}^{E}}{1-\tau^{E}}-(1-z) I \hat{z}\right] \\
& \hat{e}=-\left[1-\frac{\left(1+S^{L}-S^{E}\right) /\left(1-\tau^{E}\right)}{(1-\epsilon-\alpha) \Psi P V}\right] \hat{\tau}^{E}+\frac{1}{(1-\epsilon-\alpha) \Psi P V}\left[\frac{\hat{S}^{L}-\hat{S}^{E}}{1-\tau^{E}}-(1-z) I \hat{z}\right] .
\end{aligned}
$$

The competitive price generates demand according to (11) which attracts an equilibrium number of entrepreneurs to clear the market for innovative goods as in (2). A policy shock thus changes entrepreneurship by:

$$
\hat{E}=-\eta \hat{V}-\alpha \hat{a}-\epsilon \hat{e} .
$$

Finally, the effect on welfare results from (17) and reflects disposable income as well as consumer surplus from consumption of innovative goods. By (13), $d C S=-D d V$. Using $D=P E$, we obtain from (17):

$$
d U^{*} \equiv \hat{U}^{*}=\hat{S}^{L}-P V E \cdot \hat{V}
$$

\section{Appendix C. Taxation of venture capital}

Proof of Proposition 3. Linearize the budget $\tau^{\boldsymbol{E}}[s P V+B]+\tau^{F}[(1-s) P V-Q]=z I$ to find the feasible tax cut. Using (B.4), $Q \hat{Q}=-(1-\epsilon) s P V(\hat{P}+\hat{V})-(1-z) I \hat{z}$, and noting that $s$ is constant, one derives:

$$
\left(1-\tau^{F}\right)(1-z) I \hat{z}=\left(1-\tau^{F}\right) \alpha(1-s) P V \hat{\tau}^{F}+\left[\tau^{F}(1-\epsilon s)+\tau^{E} \epsilon s\right] P V(\hat{P}+\hat{V}),
$$

where $Q$ was replaced by (A.4d) to rewrite the tax base by $(1-s) P V-Q=\alpha(1-s) P V$. Substituting (B.6) into (B.5) yields $\hat{P}+\hat{V}=-[(1-z) I /((1-\epsilon-\alpha) \Psi P V)] \hat{z}$ which is plugged into the preceding equation to get, upon using $P V=\left[(1-z) I+1 /\left(1-\tau^{E}\right)\right] /(1-\epsilon-\alpha) \Psi$ from (A.4g):

$$
\hat{\tau}^{F}=\frac{1-\left(1-\tau^{E}\right) s \epsilon-\left(1-\tau^{F}\right)(1-s) \alpha}{\left(1-\tau^{F}\right) \alpha(1-s)} \cdot \frac{(1-z) I}{1 /\left(1-\tau^{E}\right)+(1-z) I} \hat{z} .
$$

. Since $1-s \epsilon-(1-s) \alpha=(1-\epsilon-\alpha) \Psi>0$ by $(\mathrm{A} .4 \mathrm{~g})$, the numerator of the first term is positive. Knowing the size of the tax cut, the price response in (B.6) yields [again using (A.4g)]:

$$
\hat{V}=\alpha \hat{\tau}^{F}-\frac{(1-z) I}{\Psi P V} \hat{z}=\frac{K_{1}}{\left(1-\tau^{F}\right)(1-s)} \cdot \frac{(1-z) I}{1 /\left(1-\tau^{E}\right)+(1-z) I} \hat{z},
$$




$$
K_{1} \equiv\left[1-\left(1-\tau^{E}\right) s\right] \cdot \boldsymbol{\epsilon}+\left[1-\left(1-\tau^{F}\right)(1-s)\right] \cdot(1-\boldsymbol{\epsilon}) .
$$

Finally, entrepreneurship follows from (B.8):

$$
\hat{E}=-\left[\frac{1}{1-\epsilon-\alpha}+(\eta-1)\right] \hat{V}+\frac{\alpha}{1-\epsilon-\alpha} \hat{\tau}^{F} .
$$

(a) Starting from an untaxed position, $\hat{z}<0$ yields $\hat{V}=[((1-s) \epsilon+(1-\epsilon) s / 1-s)]$. $[I /(1+I)] \hat{z}<0$ in (C.2). Combining with (C.1), $\hat{V}-(1-\epsilon) \hat{\tau}^{F}=-[(1-s \epsilon) /$ $((1-s) \alpha)] \cdot[(1-\alpha-\epsilon) I / 1+I)] \hat{z}$ and $\hat{V}-\alpha \hat{\tau}^{F}=-[(1-\epsilon-\alpha) I /(1+I)] \hat{z}$. Therefore, efforts increase with $\hat{z}<0$, see (B.2). With $\eta=1$, the policy retards entrepreneurship as it raises the success probability, $\hat{E}=-\left(\hat{V}-\alpha \hat{\tau}^{F}\right) /(1-\epsilon-\alpha)$ $<0$ by the preceding result. By (B.9), the price reduction raises welfare, $\hat{U}^{*}=-$ $P V E \cdot \hat{V}>0$.

(b) With optimal subsidies in place, we have $K_{1}=0$ in (C.2), leaving the equilibrium price unchanged, $\hat{V}=0$, which also reduces the welfare gain to zero. The policy boosts joint efforts as in (B.2) and impairs entrepreneurship, irrespective of the demand elasticity.

Proof of Proposition 4. The budget is $\tau^{E}[s P V+B]+\tau^{F}[(1-s) P V-Q]=S^{E}$. Get $\hat{S}^{E}=$ $\left(1-\tau^{E}\right)[s P V+B] \hat{\tau}^{E}+\left[\tau^{E} s+\tau^{F}(1-s)\right] P V(\hat{P}+\hat{V})+\tau^{E} B \hat{B}-\tau^{F} Q \hat{Q}$, where $s$ remains fixed as in (15), Substituting (B.4), and using (15) to rewrite the tax base as $[s P V+B]=\epsilon s P V+1 /\left(1-\tau^{E}\right)$, yields:

$$
-\frac{1-\tau^{F}}{1-\tau^{E}}\left(\hat{\tau}^{E}-\hat{S}^{E}\right)=\left(1-\tau^{E}\right) \epsilon s P V \hat{\tau}^{E}+\left[(1-s \epsilon) \tau^{F}+s \epsilon \tau^{E}\right] P V(\hat{P}+\hat{V}) .
$$

The competitive price adjustment follows from the zero profit condition and is stated in (B.6). Substituting into (B.5) yields $\hat{P}+\hat{V}=\left(\hat{\tau}^{E}-\hat{S}^{E}\right) /\left[\left(1-\tau^{E}\right)(1-\epsilon-\alpha) \Psi P V\right]$ which replaces $\hat{P}+\hat{V}$ in (C.4). Using (A.4g), $\left(1-\tau^{E}\right)(1-\epsilon-\alpha) \Psi P V=1+\left(1-\tau^{E}\right) I$ :

$$
\begin{array}{ll}
\text { (a) } \hat{\tau}^{E}-\hat{S}^{E} & =-\frac{\left(1-\tau^{E}\right) s \epsilon\left[1+\left(1-\tau^{E}\right) I\right]}{A} \cdot \hat{\tau}^{E}, \\
\text { (b) } \hat{\tau}^{E} & =\frac{A}{\left[1-\left(1-\tau^{F}\right)(1-s) \alpha+\left(1-\tau^{E}\right)^{2} s \epsilon I\right]} \cdot \hat{S}^{E}, \\
\text { (c) } A & \equiv 1-\left(1-\tau^{E}\right) s \epsilon-\left(1-\tau^{F}\right)(1-s) \alpha>0,
\end{array}
$$

where $A$ is necessarily positive by (A.4g). Using (A.4g) again, the equilibrium price response in (B.6) is $\hat{V}=\epsilon \hat{\tau}^{E}+(1-\epsilon-\alpha)\left(\hat{\tau}^{E}-\hat{S}^{E}\right) /\left(1+\left(1-\hat{\tau}^{E}\right) I\right)$. With the result in (C.5a):

$$
\begin{aligned}
& \hat{V}=K_{2} \epsilon /\left[1-\left(1-\tau^{F}\right)(1-s) \alpha+\left(1-\tau^{E}\right)^{2} s \epsilon I\right] \cdot \hat{S}^{E}, \\
& K_{2} \equiv\left[1-\left(1-\tau^{F}\right)(1-s)\right] \cdot \alpha+\left[1-\left(1-\tau^{E}\right) s\right] \cdot(1-\alpha) .
\end{aligned}
$$


(a) Starting from an untaxed state, the policy reduces venture returns in (C.6) since $K_{2}=s \alpha+(1-s)(1-\alpha)>0$. The competitive price feeds back into joint effort. Substitute (C.6) into (B.2), use (A.4g), $(1-\epsilon-\alpha) \Psi P V=1+I$, and get:

$$
\hat{a}=\frac{\hat{\tau}^{E}-\hat{S}^{E}}{1+I}>0, \quad \hat{e}=-\hat{\tau}^{E}+\frac{\hat{\tau}^{E}-\hat{S}^{E}}{1+I}>0
$$

By (C.5a), the policy raises joint efforts. Satisfying demand at lower prices requires more entrepreneurs, a higher success rate requires fewer. Starting from laissez faire, the net effect is $\hat{E}=-\eta \hat{V}-\alpha \hat{a}-\epsilon \hat{e}=\left[\left(s-(\eta-1) K_{2}\right) /(1-(1-s) \alpha+s \epsilon I)\right] \cdot \epsilon \hat{S}^{E}$. Hence, the policy retards entrepreneurship for $\eta$ close to unity. By the price cuts in (C.6), it raises consumer surplus and welfare.

(b) With first best subsidy rates in place, $K_{2}=0$ in (C.6) which eliminates the price cuts and welfare gains. With $\hat{V}=0$, joint efforts increase, see (B.2), and entrepreneurship thus unambiguously declines, see (B.8).

\section{Appendix D. Taxation of entrepreneurs}

This appendix analyzes the case of a base salary that is unrelated to performance and replaces the upfront payment $B$ of Section 3. To find the optimal compensation of the entrepreneur, the VC anticipates the effects on joint efforts as in (B.2), and maximizes her surplus subject to the new version of $P C^{E}$ as in $\left(14 \mathrm{i}^{\prime}\right)$ :

$$
\begin{aligned}
\Omega^{F}= & \max _{s, B}\left(1-\tau^{F}\right)[(1-s) P(e, a) V-B-(1-z) I]-\gamma a+\lambda \\
& \cdot\left[\left(1-\tau^{E}\right) s P(e, a) V-\beta e+(1-t) B+S^{E}-S^{L}-(1-t)\right] .
\end{aligned}
$$

The necessary conditions with respect to $B$ and $s$ are:

$$
\begin{array}{ll}
B: & \left(1-\tau^{F}\right)=(1-t) \lambda, \\
s: & {\left[\left(1-\tau^{F}\right)-\left(1-\tau^{E}\right) \lambda\right] P=\lambda\left(1-\tau^{E}\right) P_{a} s \frac{\mathrm{d} a}{\mathrm{~d} s}+\left(1-\tau^{F}\right)(1-s) P_{e} \frac{\mathrm{d} e}{\mathrm{~d} s} .}
\end{array}
$$

$B: \quad\left(1-\tau^{F}\right)=(1-t) \lambda$,

$s: \quad\left[\left(1-\tau^{F}\right)-\left(1-\tau^{E}\right) \lambda\right] P=\lambda\left(1-\tau^{E}\right) P_{a} s \frac{\mathrm{d} a}{\mathrm{~d} s}+\left(1-\tau^{F}\right)(1-s) P_{e} \frac{\mathrm{d} e}{\mathrm{~d} s}$.

To find the optimal share $s$, use (A.4a) and (B.2). Replace $1-\tau^{F}$ by $1-\tau^{F}=(1-t) \lambda$ and rearrange, using $T \equiv(1-t) /\left(1-\tau^{E}\right)$ as a short-hand:

(a) $s:(1-s-\alpha)(1-\epsilon) s=(1-s)(1-\alpha)(s-\epsilon) \cdot T$,

(b) $B: \quad B=1+\frac{S^{L}-S^{E}}{1-t}-\frac{1-\tau^{E}}{1-t}(1-\epsilon) s P V$,

$$
T \equiv(1-t) /\left(1-\tau^{E}\right) \text {. }
$$


By (D.3a), $1-s-\alpha$ and $s-\epsilon$ must be of the same sign and are both positive ${ }^{32}$, giving well understood reactions in (B.2). With the profit share thus determined, $P C^{E}$ in (27) implies the magnitude of the required base salary. Following the instructions in the first footnote of Appendix A, one can derive (15) for the case of $T=1$. Log-linearizing (D.3a) yields $\hat{s}-(s /(1-s-\alpha)) \hat{s}=(s /(s-\epsilon)) \hat{s}-(s /(1-s)) \hat{s}+\hat{T}$. Collect terms, multiply by $s-\epsilon$, expand the coefficient of $\hat{s}$ by $\epsilon-\epsilon$, and get:

$$
\hat{s}=-\frac{(s-\epsilon)(1-s)(1-s-\alpha)}{(s-\epsilon) \alpha s+(1-s)(1-s-\alpha) \epsilon} \hat{T}, \quad \hat{T} \equiv \hat{\tau}^{E}-\hat{t} .
$$

If the tax factor $T \equiv(1-t) /\left(1-\tau^{E}\right)$ increases, the capital gains tax becomes more confiscatory than the wage tax. Hence, the VC would have to offer a comparatively larger share $s$ relative to $B$ to fulfil $P C^{E}$. It is then preferable to reduce the entrepreneur's share as in (D.4) and pay a larger base salary instead.

A key step in the analysis is to determine the impact of taxation on VC profits. At this stage, we have optimally determined $s^{*}, B^{*}$, and $\lambda^{*}=\left(1-\tau^{F}\right) /(1-t)$. In all cases, we start from an untaxed position $(T=1=\lambda)$, and exploit the envelope theorem. We first compute the effect of the output price:

$$
\frac{\mathrm{d} \Omega^{F}}{\mathrm{~d} V}=\frac{1-(1-s) \alpha-s \epsilon}{1-\epsilon-\alpha} P .
$$

One may similarly calculate the other policy effects and get the differential:

$$
\begin{aligned}
\hat{\Omega}^{F}= & \frac{1-(1-s) \alpha-s \epsilon}{1-\epsilon-\alpha} P V \cdot \hat{V}-\frac{(1-s) \epsilon+(1-\epsilon) s}{1-\epsilon-\alpha}(1-\alpha) P V \cdot \hat{\tau}^{E} \\
& -\frac{(1-s)(1-\alpha)+(1-\epsilon) s}{1-\epsilon-\alpha} \alpha P V \cdot \hat{\tau}^{F}+(1-B) \cdot \hat{t}+I \cdot \hat{z}+\hat{S}^{E} \\
& -\hat{S}^{L} .
\end{aligned}
$$

In deriving the effect of $\tau$, one uses (A.4d) to write the tax base with zero profits as $(1-s) P V-Q=\alpha(1-s) P V$. The wage tax requires some comments. By reducing the outside wage income, the tax allows the $\mathrm{VC}$ to reduce the entrepreneur's compensation within the relationship. A tax on the base salary requires instead a higher gross wage $B$ to secure participation. The net effect is actually positive since the base salary falls short of wages in industry because the entrepreneur also receives a profit share. For these reasons, the wage tax actually raises $\mathrm{VC}$ profits.

\footnotetext{
32 In the symmetric case with $\alpha=\epsilon$ and $T=1$, (D.3a) implies $s=1 / 2$ while $\alpha=\epsilon<1 / 2$ by concavity of the success rate, see (9).
} 


\section{Proof of Proposition 5.}

(a) Competitive venture returns increase as in (29). When the entrepreneur's capital gains are subject to a tax, but her base salary is not, it is more costly to secure her participation by means of a profit share. Therefore, $\hat{T}=\hat{\tau}>0$ in (D.4) reduces the entrepreneur's share. Joint efforts respond as in (B.2). Despite the price increase, the net effect of the tax on joint effort is negative since (29) implies $\hat{V}-\hat{\tau}=-[(1-s)$ $(1-\alpha)(1-\varepsilon-\alpha) /(1-(1-s) \alpha-s \varepsilon)] \hat{\tau}<0$. Since the entrepreneur receives a lower equity share, she reduces her effort even more. The fact that the $\mathrm{VC}$ is left with a larger share partially offsets the negative incentive effect of the capital gains tax. Substituting (B.2), the effect on the success probability is:

$$
\hat{P}=\epsilon \hat{e}+\alpha \hat{a}=\frac{\epsilon+\alpha}{1-\epsilon-\alpha}(\hat{V}-\hat{\tau})+\frac{(1-s) \epsilon-\alpha s}{(1-\epsilon-\alpha)(1-s)} \hat{s} .
$$

With a symmetric probability in (9), $\boldsymbol{\alpha}=\epsilon$, the optimal profit share is exactly $s=1 / 2$, see (D.3a), equal to (15) in the untaxed state. While $\hat{s}<0$ shifts efforts from entrepreneurs to $\mathrm{VCs}$, its effect on the success probability is zero in this case. Since $\hat{V}-\hat{\tau}$ was shown to be negative, the success rate unambiguously declines in the symmetric case.

(b) The price increase implies a loss in consumer surplus while the increased tax revenue would boost disposable income and raise welfare. Use (A.4d) to rewrite the tax base in (28), $P V-Q=[1-(1-\alpha)(1-S)] P V$, and substitute (28) into (B.9), $\hat{U}^{*}=$ $\hat{S}-P V E \cdot \hat{V}$. After some manipulations [factoring out $(1-\alpha)(1-s) P V$ and using (A.4d)] one arrives at the welfare effect noted in (30).

Proof of Proposition 6. See (32) and (D.4) for the effects on venture returns and equity share, and (B.2) for the effects on efforts. The implications for the success probability are seen in (D.6) where the coefficient on $\hat{s}$ is reduced to zero in the symmetric case, leaving the positive influence of higher venture returns on both types of effort. (b) Substitute (31) and (32) into (33) and rearrange to obtain the welfare result.

\section{References}

Aghion, P., Bolton, P., 1992. An 'incomplete contracts' approach to financial contracting. Review of Economic Studies 59, 473-494.

Aghion, P., Tirole, J., 1994. The management of innovation. Quarterly Journal of Economics 109, 1185-1209.

Berglöf, E., 1994. A control theory of venture capital finance. Journal of Law, Economics and Organization 10, $247-267$.

Botazzi, L., Da Rin, M., 2002. Venture capital in europe: Euro.NM and the financing of European innovative firms. Economic Policy 7, 229-269.

Casamatta, C., 2002. Financing and advising: optimal financial contracts with venture capitalists. CEPR DP 3475 .

Dewatripont, M., Tirole, J., 1994. A theory of debt and equity: diversity of securities and manager-shareholder congruence. Quarterly Journal of Economics 109, 1027-1054.

Gompers, P.A., Lerner, J., 1998. What drives venture capital fundraising? Brookings Papers on Economic Activity-Microeconomics, pp. 149-192. 
Gompers, P.A., Lerner, J., 1999. The Venture Capital Cycle. MIT Press, Cambridge.

Gompers, P.A., Lerner, J., 2001. The venture capital revolution. Journal of Economic Perspectives 15, 145 - 168.

Gordon, R.H., 1998. Can high personal tax rates encourage entrepreneurial activity. IMF Staff Papers 45 (1), $49-80$.

Hart, O., 2001. Financial contracting. Journal of Economic Literature 39, 1079-1100.

Hellmann, T., 1998. The allocation of control rights in venture capital contracts. Rand Journal of Economics 29, $57-76$.

Hellmann, T., Puri, M., 2000. The interaction between product market and financing strategy: the role of venture capital. Review of Financial Studies 13, 959-984.

Hellmann, T., Puri, M., 2002. Venture capital and the professionalization of start-up firms. Journal of Finance 57, 169-197.

Holmstrom, B., 1982. Moral hazard in teams. Bell Journal of Economics 13, 324-340.

Inderst, R., Müller, H.M., 2002. Venture capital contracts and market structure. CEPR DP 3203.

Kanniainen, V., Keuschnigg, C., 2003. The optimal portfolio of start-up firms in venture capital finance. CESifo WP No. 381. Journal of Corporate Finance 9, 521-534.

Kaplan, S.N., Strömberg, P., 2000. Financial contracting theory meets the real world: an empirical analysis of venture capital contracts. CEPR DP 2421. Review of Economic Studies, in press.

Kaplan, S.N., Strömberg, P., 2001. Venture capitalists as principals: contracting, screening, and monitoring. American Economic Review 91, 426-430.

Keuschnigg, C., 2002. taxation of a venture capitalist with a portfolio of firms. CESifo WP No. 813.

Keuschnigg, C., Nielsen, S.B., 2001. Public policy for venture capital. International Tax and Public Finance 8 (4), 557-572.

Keuschnigg, C., Nielsen, S.B., 2001b. Progressive Taxation, moral hazard, and entrepreneurship. Public Economic Theory, in press.

Keuschnigg, C., Nielsen, S.B., 2002. Start-ups, venture capitalists, and the capital gains tax. CESifo WP 742 and CEPR WP 3263.

Keuschnigg, C., Nielsen, S.B., 2003. Tax policy, venture capital, and entrepreneurship. Journal of Public Economics $87,175-203$.

Kortum, S., Lerner, J., 2000. Assessing the contribution of venture capital to innovation. Rand Journal of Economics 31, 674-692.

Lülfesmann, C., 1999. Start-up firms, venture capital financing, and renegotiation. University of Bonn, Mimeo. McAfee, R.P., McMillan, J., 1991. Optimal contracts for teams. International Economic Review 32, $561-577$.

Poterba, J.M., 1989a. Capital gains tax policy toward entrepreneurship. National Tax Journal 42, 375-389.

Poterba, J.M., 1989b. Venture capital and capital gains taxation. In: Lawrence, H.S. (Ed.), Tax Policy and the Economy, vol. 3. MIT Press, Cambridge, pp. 47-67.

Repullo, R., Suarez, J., 1999. Venture capital finance: a security design approach. CEMFI, Madrid, Mimeo.

Sahlman, W., 1990. The Structure and governance of venture capital organizations. Journal of Financial Economics $27,473-522$.

Schmidt, K.M., 2002. Convertible securities and venture capital finance. CEPR DP 2317. Journal of Finance, in press.

Tirole, J., 2001. Corporate governance. Econometrica 69, 1-35. 